\title{
Foliar fungi and plant diversity drive ecosystem carbon fluxes in experimental prairies
}

\author{
Mayank Kohli ${ }^{1}$, Jeremiah Henning ${ }^{2}$, Elizabeth Borer $^{1}$, Linda Kinkel ${ }^{1}$, and Eric Seabloom ${ }^{1}$ \\ ${ }^{1}$ University of Minnesota \\ ${ }^{2}$ University of South Alabama
}

June 25, 2020

\begin{abstract}
Plant diversity and plant-consumer interactions likely interact to influence ecosystem carbon fluxes but experimental evidence is scarce. We examined how experimental removal of foliar fungi, soil fungi and arthropods from experimental prairies planted with 1, 4 or 16 plant species affected instantaneous rates of carbon uptake (GPP), ecosystem respiration (Re) and net ecosystem exchange (NEE). Increased plant diversity doubled plant biomass, in turn doubling GPP and Re, but NEE remained unchanged. Removing foliar fungi increased GPP and NEE, with greatest effects at low plant diversity. After accounting for plant biomass, we found that removing foliar fungi increased mass-specific flux rates by $48 \%$ by altering plant species composition and community-wide foliar nitrogen content. However, this elevated NEE effect disappeared when soil fungi and arthropods were also removed, demonstrating ecosystem-scale impacts of interactions among consumer groups. Thus, plant diversity and consumer context determine the effects of plant-fungal interactions on ecosystem carbon fluxes.
\end{abstract}

\section{Foliar fungi and plant diversity drive ecosystem carbon fluxes in experimental prairies}

Mayank Kohli ${ }^{1 *}$, Jeremiah A. Henning ${ }^{1,}$, Elizabeth Borer ${ }^{1}$, Linda Kinkel ${ }^{3}$, Eric W. Seabloom ${ }^{1}$

${ }^{1}$ Department of Ecology, Evolution and Behavior, University of Minnesota, Twin Cities

${ }^{2}$ Department of Biology, University of South Alabama

${ }^{3}$ Department of Plant Pathology, University of Minnesota, Twin Cities

* Correspondence: 1987 Upper Buford Circle, Saint Paul, MN, USA 55108; mayankkohli22@gmail.com; $+1-651-703-1362$

Author contributions: EB, ES and LK organized logistics and funding to maintain the heterotroph removal experiment. ES, JH and EB conceived this study. JH organized the setup for collecting field data and collected data with MK. MK analyzed data with inputs from ES. MK wrote the first draft with input from JH. All authors provided input on revisions.

Running title: Foliar fungi and plant diversity drive grassland $\mathrm{CO}_{2}$ fluxes

Keywords: biodiversity loss, ecosystem $\mathrm{CO}_{2}$ fluxes, consumer effects, plant-pathogen interaction, plantherbivore interaction, biodiversity-ecosystem function

Type of article: Letters

Number of words: Abstract (150), Main text (4996)

Number of references: 67

Number of figures: 6 
Number of tables: 0

Supplementary information: 3 figures and 13 tables

Data accessibility

Data supporting the results will be archived in a public repository such as Dryad and a DOI will be included at the end of the article upon acceptance.

Abstract (150 words):

Plant diversity and plant-consumer interactions likely interact to influence ecosystem carbon fluxes but experimental evidence is scarce. We examined how experimental removal of foliar fungi, soil fungi and arthropods from experimental prairies planted with 1, 4 or 16 plant species affected instantaneous rates of carbon uptake (GPP), ecosystem respiration $\left(\mathrm{R}_{\mathrm{e}}\right)$ and net ecosystem exchange (NEE). Increased plant diversity doubled plant biomass, in turn doubling GPP and $\mathrm{R}_{\mathrm{e}}$, but NEE remained unchanged. Removing foliar fungi increased GPP and NEE, with greatest effects at low plant diversity. After accounting for plant biomass, we found that removing foliar fungi increased mass-specific flux rates by $48 \%$ by altering plant species composition and community-wide foliar nitrogen content. However, this elevated NEE effect disappeared when soil fungi and arthropods were also removed, demonstrating ecosystem-scale impacts of interactions among consumer groups. Thus, plant diversity and consumer context determine the effects of plant-fungal interactions on ecosystem carbon fluxes.

\section{Introduction}

Plant production, or the carbon fixed by primary producers, is the energetic base of all food webs and also serves to regulate global climate (Beer et al. 2010). In terrestrial systems, plant diversity and plant-consumer interactions can have strong impacts on plant production when measured as plant biomass (Gastine et al 2003; O'Connor et al. 2017; Seabloom et al. 2017). However, ecosystems with similar plant biomass or the standing stock of carbon in plant tissue at the end of season may differ in ecosystem carbon flux rates. Understanding the effects of biotic interactions on changes in instantaneous carbon flux rates will improve our understanding of the structure of ecosystems (e.g., biomass distribution across trophic levels, energy fluxes between organisms), help further integrate community ecology within ecosystem ecology, and will lay the groundwork to incorporate biological interactions in the next generation of global carbon models.

Human-mediated global changes are leading to an unprecedented decline in biodiversity across the tree of life and a reorganization of foodwebs that will likely have significant effects on ecosystem function (Naeem et al. 1994; McGrady-Steed et al. 1997; Barnosky et al. 2011; Dirzo et al. 2014; McCauley et al. 2015; Young et al. 2016; Seabloom et al. 2017; Rosenberg et al. 2019). While the effects of changes in plant diversity on plant biomass and production have been well documented (Gastine et al 2003; O'Connor et al. 2017), few studies have examined the direct effects of plant diversity on instantaneous carbon flux rates (Stocker et al. 1999; Wilsey \& Polley 2004; Milcu et al. 2014). Fewer still have examined the effects of plantheterotroph interactions on ecosystem carbon fluxes (e.g., Naeem et al. 1995; Strickland et al. 2013). Yet, direct measurements of instantaneous carbon fluxes in response to altered plant diversity and heterotroph community composition will clarify the role of plant diversity and heterotroph groups in altering carbon flux rates. The effects of plant-heterotroph interactions on ecosystem fluxes can also reveal the role of plant diversity in supporting consumer foodwebs, an important question given the growing concern about changes in diversity and abundances of heterotrophs (Dirzo et al. 2014; Ceballos et al. 2017) such as dramatic decline in terrestrial arthropods (Hallmann et al. 2017; Loboda et al. 2018; Seibold et al. 2019; van Klink et al. 2020) and the interactive effects of reduced plant diversity, nutrient deposition and climatic changes on the occurrence and spread of plant diseases (Mitchell et al. 2002; Strengbom et al. 2002; Anderson et al. 2004; Garrett et al. 2006).

Plant diversity can influence instantaneous ecosystem carbon fluxes via its effects on plant biomass (Stocker et al. 1999; O'Connor et al. 2017) or on mass specific flux rates (Fig. 1). For example, plant nitrogen (N) content, which strongly predicts mass-specific, leaf-scale photosynthesis and respiration rates (Reich et al. 
1997; Reich et al. 2006), can change in response to plant diversity (Guiz et al. 2016, 2018). These changes can arise both at the species scale due to an intraspecific change in nitrogen content (Borer et al. 2015; Guiz et al. 2018), and community-wide due to changes in the relative abundance of plant species that differ in their photosynthetic or respiration rates, because of their photosynthetic pathway (e.g., C3 vs. C4) or tissue nutrient concentration (e.g., \% $\mathrm{N}$ difference between leguminous forbs and grasses) (Guiz et al. 2016).

Plants exist in a milieu of heterotrophs including consumers, mutualists and pathogens, all of which can rely on and can influence ecosystem carbon fluxes via their effects on plant biomass or on mass-specific flux rates (Fig. 1). Consumption by herbivores or infection fungal pathogens can reduce both aboveground and belowground plant biomass (Mitchell 2002; Seabloom et al. 2017) and alter the plant diversity-productivity relationship (Eisenhauer et al. 2012; Seabloom et al. 2017; Wang et al. 2019), directly affecting the amount of carbon fixed and respired. Further, heterotrophs affect the nutrient and water availability to and acquisition by plants, which can affect the instantaneous rates of photosynthesis and respiration. For example, mycorrhizal fungi can increase acquisition of phosphorous and water (Bolan 1991; Smith \& Read 2008), and herbivores and detritivores can impact nitrogen mineralization in soil (Hobbie and Villéger 2015) and water transport in plant tissue (Nabity et al. 2009). Finally, plants also respond to disease and defoliation by a direct down-regulation of photosynthesis (Mitchell 2003; Bilgin et al. 2010). Like plant-plant interactions, plantherbivore and plant-fungal interactions also influence plant nitrogen content at the species and community scale (Pastor et al. 1993; Pastor \& Cohen 1997; Ritchie et al. 1998; Borer et al. 2015), potentially driving changes in ecosystem carbon fluxes (Reich et al. 1997).

Here, we report changes in the instantaneous fluxes of $\mathrm{CO}_{2}$ in experimental prairie communities with varying plant species richness (1, 4 or 16 plant species, Tilman et al. 1996) from which heterotroph groups (arthropods, foliar fungi and soil fungi) were experimentally removed either singly or all together (Borer et al. 2015). We partitioned $\mathrm{CO}_{2}$ flux into uptake via gross primary production (GPP), respiration at the whole-plot scale, or ecosystem respiration $\left(\mathrm{R}_{\mathrm{e}}\right)$, and their difference, the net ecosystem exchange (NEE) (Lasslop et al. 2010). We examined the effects of plant diversity and foodweb manipulation on total plot scale fluxes and fluxes per unit plant biomass to tease apart biomass driven effects from effects on mass-specific flux rates. To further understand how ecosystem carbon fluxes are affected by biotic interactions, we examined mass specific flux rates in relation to the composition and foliar nitrogen content of the plant community.

We generated a priori hypotheses based on existing literature where possible:

(H1) Total GPP and $R_{e}$ will increase with plant diversity; the overall effect of NEE will depend on the relative changes in GPP and $R_{e}$. Previous research suggests that high diversity plots accumulate more biomass (O'Connor et al. 2017) which results in increased soil carbon (e.g., Yang et al. 2019), we expected GPP to increase more than $\mathrm{R}_{\mathrm{e}}$ with increasing plant diversity.

(H2) Heterotroph removal will lead to an increase in total GPP and $R_{e}$. As plant communities accumulate more above and belowground biomass when heterotrophs are removed (Maron et al. 2011; Seabloom et al. 2017), we expected an overall increase in NEE.

(H3) Removal of foliar fungi and arthropods will lead to an increase in mass-specific GPP and reduction in $R_{e}$. Both pathogens and herbivores have been shown to increase plant respiration rate and suppress photosynthetic rate (Mitchell 2003; Lambers et al. 2008; Nabity et al. 2009; Bilgin et al. 2010; Strickland et al. 2013).

(H4) The effects of heterotroph removal on carbon fluxes will depend on the plant community (e.g., species richness, foliar chemistry). Previous research has shown that the intensity of herbivory and pathogen infection vary with host community (e.g., species richness, relative abundance of host, Mitchell et al. 2002). Further, previous studies have also shown that the plant and heterotroph communities interactively influence plant chemistry (Borer et al. 2015).

\section{Methods}

The work described here was conducted at the Cedar Creek Ecosystem Science Reserve (CDR), East Bethel, 
Minnesota, part of the U.S. Long Term Ecological Research (LTER) Network (Latitude $45.4^{\circ} \mathrm{N}, 93.2^{\circ} \mathrm{W}$ ). CDR is situated on a sandy outwash plain formed during Wisconsin glaciation 11,000 ybp. These infertile have very low nitrogen and support low productivity grasslands (Fay et al. 2015). Mean annual precipitation and mean annual temperature at the site are $750 \mathrm{~mm}$ and $6^{\circ} \mathrm{C}$ respectively (Borer et al. 2015). The heterotroph manipulation experiment was conducted within an existing plant diversity experiment (Tilman et al. 2001). Below, we describe the experiment in detail.

The heterotroph manipulation experiment was nested within a long-term grassland plant diversity experiment initiated in 1994 (Tilman et al. 2001). Heterotroph manipulation treatments were established in 2008 in 33 of the $9 \mathrm{~m} \times 9 \mathrm{~m}$ experimental plots, with planted richness of $1(\mathrm{n}=15), 4(\mathrm{n}=9)$ and 16 species $(\mathrm{n}=9)$. In each of the 33 experimental plots, 5 treatments (control, insecticide, foliar fungicide, soil fungicide, and all pesticides combined) were randomly assigned to subplots (1 per treatment per plot) of $1.5 \mathrm{~m} \mathrm{x} 2 \mathrm{~m}$ for a total of 165 experimental subplots (33 diversity plots $\mathrm{x} 5$ treatments). Subplots were separated by $0.5 \mathrm{~m}$ wide buffer strips to prevent drift. The experiment was fenced to exclude deer.

All pesticides were applied regularly throughout the growing season from mid-April to end of August each year. The treatments were maintained as follows: foliar fungicide as biweekly application of Quilt (Syngenta Crop Protection, Inc., Greensboro, NC), a combination of Azoxystrobin (7.5\%) and Propiconazole (12.5\%); soil fungicide as monthly applications of Ridomil Gold SL (Syngenta Crop Protection, Inc., Greensboro, NC), a soil drench fungicide containing Mefenoxam (45.3\%); and insecticide as biweekly applications of Marathon II (OHP, Inc., Mainland, PA; 21.4\% Imidacloprid). Once or twice each season, Malathion was applied instead of Marathon II to reduce the possibility of insecticide adaptation by the local insect populations. Previous work from this experiment has shown that these heterotroph removal treatments lower foliar damage by arthropods and by foliar fungi by approximately 50-67\% (Borer et al. 2015). Results from a greenhouse experiment showed that none of the pesticides had any direct effects on plant growth in the absence of heterotrophs (Seabloom et al. 2017).

\section{Ecosystem $\mathrm{CO}_{2}$ exchange}

During the peak of the growing season (August 2018), we used a Li-Cor 7500 open-path infrared gas analyzer (IRGA; Li-Cor, Lincoln, Nebraska, USA) to measure changes in $\mathrm{CO}_{2}$ concentration and air temperature in the headspace of a chamber placed over the plots. We placed the IRGA inside a $1 \mathrm{~m}^{3}$ cube that was made from a polyvinyl chloride (PVC) frame and transparent 6-mil plastic sheeting (Polar Plastics Inc., Oakdale, MN, USA), with internal fans to ensure adequate mixing of air, sealed to the ground with two $1.27 \mathrm{~cm}$ diameter $\times 3.04 \mathrm{~m}$ length steel chains wrapped around the base of the chamber. Each measurement cycle began by lowering the chamber, sealing it, and once a consistent rate of $\mathrm{CO}_{2}$ exchange was achieved (typically less than a minute), we began logging a two minute flux measurement in the light at a sampling frequency of $0.5 \mathrm{~Hz}$. At time of flux measurement, we also measured photosynthetically active radiation (PAR) using a MQ-100 Apogee PAR meter (Apogee Instruments, Logan, UT, USA) that was mounted to the top of the IRGA just below upper surface of the chamber. Full light measurements were recorded in a minimum of $900 \mu \mathrm{mol} \mathrm{m} \mathrm{m}^{-2} \mathrm{~s}^{-1}$ between the hours of 0930 and 1530. For each full light measurement, we calculated net ecosystem exchange (NEE; $\mu \mathrm{mol} \mathrm{m} \mathrm{s)} \mathrm{using} \mathrm{Eqn} 1$ to quantify the maximum continuous exchange of $\mathrm{CO}_{2}$ between the atmosphere, vegetation and soil.

$\mathrm{NEE}=\left(\rho^{*} V *(d C / d t) / A\right)(1)$

In Eqn $1, \rho$ is the air density $\left(\mathrm{mol}\right.$ air $\left.\mathrm{m}^{-3}\right)$, defined as $P / R T$, where $P$ is the average pressure $(\mathrm{Pa}), R$ is the ideal gas constant $\left(8.314 \mathrm{~J} \mathrm{~mol}^{-1}\right.$ air $\left.\mathrm{K}^{-1}\right)$, and $T(\mathrm{~K})$ is the mean temperature. $V$ is the chamber volume $(1$ $\left.\mathrm{m}^{3}\right), d C / d t$ is the slope of the chamber $\mathrm{CO}_{2}$ concentration against time ( $\mu \mathrm{mol} \mathrm{CO}_{2}$ mol air $\mathrm{s}$ ), and $A$ is the surface area of the ground $\left(1 \mathrm{~m}^{2}\right)$ within the chamber.

In order to calculate standardized NEE values to a fixed light level $\left(\mathrm{PAR}=800 \mu \mathrm{mol} \mathrm{m} \mathrm{m}^{-2} \mathrm{~s}^{-1}\right)$ and to partition flux measurements between ER and GPP, we used garden shade cloth (Agfabric, Wellco Industries Inc., Corona, CA, USA) to reduce light penetrating our chamber in order to create an NEE light response curve (Lasslop et al. 2010; Williams et al. 2014). Each shade cloth reduced light availability by $50 \%$ 
within chamber. We measured continuous $\mathrm{CO}_{2}$ exchange over two minute intervals with a single layer of garden shade cloth ( $\sim 50 \%$ of ambient light), as well as two layers of shade cloth ( $25 \%$ of ambient light). Finally, we used a $100 \%$ light blocking tarp to measure carbon flux at $0 \mu \mathrm{mol} \mathrm{m} \mathrm{m}^{-2} \mathrm{~s}^{-1}$ PAR (i.e. Ecosystem Respiration, $\mathrm{R}_{\mathrm{e}}$ ). From the four light measurements (Full sun, half-light, quarter-light, and no light), we fit both hyperbolic and linear functions to predict NEE at a standardized light of PAR $=800 \mu \mathrm{mol} \mathrm{m}{ }^{-2}$ $\mathrm{s}^{-1}\left(\mathrm{NEE}_{800}\right)$. We compared $\mathrm{r}$-squared values for these two fits and found that the hyperbolic function always fit better. Negative NEE values indicate fluxes from the atmosphere to the ecosystem,i.e. net carbon uptake, and positive values indicate net fluxes to the atmosphere from the ecosystem, i.e. net carbon emissions. NEE values, standardized by light, were used to compare NEE fluxes across subplots and plots. Next, we calculated GPP (Lasslop et al. 2010) by subtracting $R_{e}$ from the standardized NEE values (Eqn 2).

Gross Primary Productivity $(\mathrm{GPP})=\mathrm{NEE}_{800}-\mathrm{R}_{\mathrm{e}}(2)$

To account for differences in plant biomass among treatments, we also calculated NEE, $\mathrm{R}_{\mathrm{e}}$, and GPP that were standardized per gram of total plant biomass (i.e., sum of above and below-ground biomass). In early August 2018, we estimated above- and below-ground plant biomass in all subplots. To estimate aboveground plant biomass we clipped vegetation in two $0.1 \times 1 \mathrm{~m}$ strips, dried and weighed this vegetation to the nearest $0.001 \mathrm{~g}$; to estimate root biomass, we took 3 soil cores of $5 \mathrm{~cm}$ diameter and $30 \mathrm{~cm}$ depth, sieved all roots, washed and dried them, and then weighed them to the nearest $0.001 \mathrm{~g}$. By standardizing carbon flux measurements to units of plant biomass, we were able to parse differences in carbon fluxes (NEE, GPP, and $R_{e}$ ) between different subplots and plots caused due to differences in plant biomass from those driven by other factors that mediate carbon fluxes (e.g., plant trait shifts, plant community composition, microbial community changes, etc.). Mass-specific NEE ( $\left.\mathrm{NEE}_{\mathrm{msp}}\right)$ was calculated as in Eqn 3.

$\mathrm{NEE}_{\mathrm{msp}}=\mathrm{NEE}_{800} /$ Total plant biomass $\left(\mathrm{g}^{-1} \mathrm{~m}^{-2}\right)(3)$

Plant community composition, and community wide foliar $N$ content

We related changes in carbon fluxes to foliar traits and plant community composition. Specifically, we examined how abundances of plant functional groups (C3 and C4 grasses, leguminous and non-leguminous forbs), and plant nitrogen (N) content (weighted average for the whole community) influenced mass specific GPP and $R_{e}$. Species cover data were visually estimated in a $1 \mathrm{~m} \times 1 \mathrm{~m}$ area within each subplot. Cover data were aggregated by plant functional type. Community weighted foliar $\mathrm{N}$ data was measured by homogenizing aboveground plant biomass and analyzing subsamples of homogenized biomass. For this, vegetation was clipped in 2 clip strips, $10 \mathrm{~cm}$ wide $\times 6 \mathrm{~m}$ long. Samples were air dried at 40 degrees $\mathrm{C}$, ground and homogenized, and subsequently analyzed using a C-N analyzer (NA1500, Carlo-Erba Instruments or ECS 4010, COSTECH Analytical Technologies Inc.).

\section{Statistical analyses}

We used linear mixed effects models to test for effects of plant diversity and heterotroph removals on carbon fluxes using thenlme package (Pinheiro, Bates, DebRoy, Sarkar \& R Core Team 2019) in R software (R Core Team 2019). We performed these analyses with both total fluxes and mass-specific fluxes obtained by dividing total fluxes by total plant biomass. Total and mass-specific fluxes were log transformed. Plant diversity was considered a factor variable with three distinct levels (1, 4 and $16 \mathrm{sp}$ ). In mixed model specification, plant diversity and heterotroph removal treatments were included as fixed effects. To account for the nested split plot design of the experiment, we included subplots (heterotroph removal treatments) nested within plots (plant diversity) as random intercepts in our mixed models. Full model equations are provided with the model results (Tables 1-6). All figures were generated using the 'ggplot2' package (Wickham 2009). To examine percent nitrogen content and relative abundances of different functional types we constructed generalized linear mixed effects models with a logit link using 'glmer' function in lme4 package (Bates et al. 2015). We performed path analysis with the most important variables from bivariate analyses to determine the relative importance of different pathways via which plant diversity and heterotroph removals influenced carbon fluxes. To do so, we constructed a structural equation model using the 'piecewiseSEM' package (Lefcheck et al. 2016). 


\section{Results}

Effects of plant diversity and heterotroph removal on plant biomass

As plant diversity increased from 1 to 16 species, total plant biomass increased from an average of 730 g.m ${ }^{-2}$ to 1120 g. $\mathrm{m}^{-2}$ in plots where heterotrophs were present (Fig. S1, Table S1). Experimental removal of foliar fungi increased plant biomass in the mid and high diversity plots (Table S1, Fig. S1).

Effects of plant diversity and heterotroph removal on total plot level C fluxes

As plant diversity increased from 1 to 16 species in control plots, i.e. in the presence of all heterotrophs, NEE increased from an average of $3.95( \pm 0.96)$ in monocultures to $6.9( \pm 1.36) \mu \mathrm{mol} \mathrm{CO}_{2} \mathrm{~m}^{-2} \mathrm{~s}^{-1}$ in 16 species plots, but this trend was not statistically significant (Table S2, Fig. $2 \mathrm{C}$ ). Mean GPP and $\mathrm{R}_{\mathrm{e}}$ roughly doubled along this gradient of plant diversity (Tables S3-S4, Figs. 2A, B). GPP increased from $8.37( \pm 1.06)$ $\mu \mathrm{mol} \mathrm{CO} \mathrm{Cm}^{-2} \mathrm{~s}^{-1}$ (mean \pm 1 s.e.) in monocultures to $16.18( \pm 2.03)$ in the 16-species plots, and $\mathrm{R}_{\mathrm{e}}$ increased from $4.42( \pm 0.36)$ in monocultures to $9.28( \pm 1.88) \mu \mathrm{mol} \mathrm{CO}_{2} \mathrm{~m}^{-2} \mathrm{~s}^{-1}$ in the high diversity plots. Thus, the increase in GPP with plant diversity was offset by the increase in $R_{e}$ such that there was no significant effect of plant diversity on NEE.

Removal of all heterotrophs simultaneously did not affect NEE, GPP or $R_{e}$ (Tables S2-S4, Fig. 2). Among all heterotrophs, only foliar fungi influenced carbon fluxes when removed independently. Removal of foliar fungi increased GPP by an average of $54 \%$ at each plant diversity level (Table S3, Fig 2A). Because GPP increased with plant diversity (as noted above), the absolute change in GPP due to removal of foliar fungi was greatest in monocultures and declined with increasing plant diversity. Heterotroph removal did not significantly influence $R_{e}$ (Table S4, Fig. 2B). Thus, plots where foliar fungi had been removed had greater net carbon uptake: compared to the control plots, NEE increased by $45 \%$ in the subplots where foliar fungi were removed and this effect was strongest in low diversity communities (Table S3, Fig. 2C). Foliar fungi only impacted total fluxes when all other consumer groups were present; total fluxes in treatment and control plots were the same when arthropods and soil fungi were removed in addition to foliar-fungi, demonstrating that plant-foliar fungal interactions determining carbon flux rates depended the heterotroph foodweb context (Tables S2-S4; Fig. 2).

\section{Effects of plant diversity and heterotroph removal on mass-specific C fluxes}

After accounting for the positive effects of plant diversity and removal of foliar fungi on plant biomass (Seabloom et al. 2017; Fig. S1, Table S1), we found that there was no main effect of plant diversity on mass-specific C fluxes. Simultaneous removal of all heterotrophs and independent removal of arthropods or soil fungi did not affect mass-specific fluxes. However, independent removal of foliar fungi increased both mass-specific GPP and $R_{e}$ with an overall increase in mass-specific NEE, i.e., a greater net carbon uptake per unit plant mass (Tables S5-S7, Fig. 3). The effect of foliar fungi on mass-specific fluxes was greatest at low plant diversity.

\section{Relationship between plant community, $N$ concentration, and carbon fluxes}

Removal of foliar fungi or soil fungi reduced the relative abundance of $\mathrm{C} 4$ grasses and increased leguminous forbs (Table S8, Fig. S2). Mass specific fluxes (GPP and $\mathrm{R}_{\mathrm{e}}$ ) declined with increasing abundance of $\mathrm{C} 4$ plants and increasing belowground biomass (Table S9, Fig. 4), and increased with community-wide foliar N content (Table S10, Fig. 5) as would be expected from a shift towards a more resource conservative plant strategy. These trends were interrelated: community foliar $\mathrm{N}$ content increased as the relative abundance of leguminous forbs increased, and decreased with an increase in $\mathrm{C} 4$ grasses and in belowground biomass $(\mathrm{p}<0.001$, Table S11, Fig. 6). Removal of heterotrophs weakened the relationship between mass-specific fluxes and foliar N content (Table S10) and between foliar N content and belowground biomass (Table S11).

\section{Path analyses}

Path analyses revealed that the abundance of $\mathrm{C} 4$ grasses and plant biomass directly influenced mass-specific fluxes, not via their negative effects on community foliar N content (Table S12, Fig. S3). Thus, foliar fungi 
and soil fungi indirectly influenced mass-specific fluxes by increasing the relative abundance of $\mathrm{C} 4$ grasses (Fig. S3).

\section{Discussion}

Our study demonstrates a key role of biotic interactions, particularly between plants and foliar fungi, in ecosystem carbon flux rates. The effects of plant diversity were driven primarily by changes in plant biomass, whereas effects of foliar fungi were driven by a combination of changes in plant biomass, plant community composition and foliar chemistry. In support of $H 1$, declining plant diversity reduced GPP and $\mathrm{R}_{\mathrm{e}}$, because of the lower plant biomass in low diversity communities. In contrast, in partial support of $H_{2}$ and $H 3$, removal of foliar fungi increased carbon fluxes, because of both an increase in plant biomass and in mass-specific rates of GPP, $\mathrm{R}_{\mathrm{e}}$ and NEE. Removal of foliar fungi increased the relative abundance of $\mathrm{N}$ rich leguminous forbs and suppressed $\mathrm{C} 4$ grasses, increasing community wide foliar $\mathrm{N}$ content and thereby mass specific flux rates. Contrary to our (H3) expectations, removal of arthropods and soil fungi did not significantly impact instantaneous carbon fluxes. Effects of foliar fungi were mediated by plant and heterotroph community context, in support of $\mathrm{H}_{4}$ - e.g., the impacts of foliar fungi were strongest in low diversity plant communities when arthropods and soil fungi were present (i.e. not experimentally removed).

Effects on plot scale fluxes via changes in plant biomass

This work suggests that the increase in plant biomass with plant diversity directly increased ecosystem rates of carbon uptake and release. In particular, increasing plant diversity from 1 to 16 species nearly doubled both carbon uptake (GPP) and ecosystem respiration $\left(\mathrm{R}_{\mathrm{e}}\right)$, mirroring the increase in total plant biomass with plant diversity in this experiment (Reich et al. 2012). After accounting for the increase in plant biomass, carbon fluxes remained constant across the gradient of plant diversity. Thus, in the experimental grassland communities at Cedar Creek, standing plant biomass is a good predictor of ecosystem carbon fluxes (see Fig. 1). Our findings are supported by those of Stocker et al. (1999), who reported a linear relationship between the increase in plant biomass and in ecosystem carbon fluxes with increasing plant diversity.

Path analyses suggest that changes in plant biomass in response to heterotroph removal did not contribute significantly to changes in carbon fluxes in this study. Compared to previous studies from this and other experiments at Cedar Creek that have shown that foliar fungi and arthropods strongly suppress plant biomass in these prairies (Mitchell 2003; Seabloom et al. 2017; Kohli et al. 2019), we found that foliar fungi had weakly significant effect and arthropods had no effect on plant biomass in our plots. Perhaps this is because, unlike these multi-year studies, we examined fluxes and biomass in only a subset of the experimental plots and only in a single study year. Thus, it is likely that the overall effects of heterotrophs on instantaneous carbon fluxes reported here underestimate the long-term effects.

Effects on mass specific fluxes via changes in plant community

Our results reveal the complex nature of the relationship between the plant community, heterotroph foodweb and ecosystem carbon fluxes. Plant community compositional change in response to heterotroph removal treatments influenced grassland carbon fluxes via changes in community-wide plant nitrogen content. In concordance with and previously reported patterns at organ and plant scale (Reich et al. 1997; Reich et al. 2006; Reich et al. 2008), we found a positive correlation between community wide mass-specific plant nitrogen and ecosystem carbon flux rates. In the presence of heterotrophs, $\mathrm{C} 4$ grasses, which have traits characterizing 'slow' plant economics (Wright et al. 2004) e.g., low tissue N content and greater root biomass, dominated plant mixtures. As a result, community belowground biomass increased and community wide foliar $\mathrm{N}$ content decreased as relative abundance of $\mathrm{C} 4$ plants increased. In turn, these led to lower massspecific rates of ecosystem $\mathrm{CO}_{2}$ uptake and respiration (Tjoelker et al. 2005). However, in the absence of foliar or soil fungi, the relative cover of $\mathrm{C} 4$ grasses declined while that of leguminous forbs increased, supporting previous observations that pathogens suppress legumes (Allan et al. 2010; Borer et al. 2015; Seabloom et al. 2018) and promote slow growing species (Cappelli et al. 2020). The increase in legumes and decrease in $\mathrm{C} 4$ abundance increased community $\mathrm{N}$ content and thus mass specific flux rates. Thus, the effects of foliar and soil fungi on plant community composition scaled up to influence ecosystem carbon fluxes. 
Changes in the composition of the plant community and community wide foliar $\mathrm{N}$ content were not sufficient to explain patterns observed here. For example, removal of foliar fungi caused the greatest increase in leguminous forbs and decrease in C4 grasses in the high diversity plots (Seabloom et al. 2018), yet increased mass specific carbon fluxes most strongly in low diversity communities. Further, although bivariate analyses showed that mass-specific flux rates increased as community $\mathrm{N}$ content increased, path analysis suggested that this is not an important mechanism underlying the effects of plant diversity and heterotrophs on carbon fluxes. This is supported by our findings that the relationship between $\mathrm{N}$ content and flux rates, and the decline in $\mathrm{N}$ content with belowground biomass were both weakened by the removal of heterotrophs. Together, these results suggest that heterotrophs may alter the scaling of carbon exchange rates with plant nitrogen content (Reich et al. 1997; Wright et al. 2004; Reich et al. 2006). Some of this divergence might be reconciled by previously reported intraspecific responses to treatments. Specifically, foliar N content of four abundant species decreased and increased in response to removal of foliar fungi and arthropods, respectively, from low diversity plots (Borer et al. 2015), likely counteracting some of the effects of changes in plant community composition on community-wide foliar $\mathrm{N}$ content. It is also possible that in the absence of heterotrophs, more $\mathrm{N}$ became available for plant (rather than heterotroph) function (Strengbom et al. 2002; El-Hajj et al. 2004), leading to an increase in carbon flux despite a decline in foliar N. These findings pave the way for further research into how consumers alter fundamental relationships between plant traits and functioning. Our findings emphasize the importance of incorporating plant-consumer interactions to link organ- and individual-scale patterns (such as flux- $\mathrm{N}$ content relationship) to whole communities and ecosystems (Schmitz 2010).

Manipulating multiple heterotrophs independently and simultaneously in the same study allowed us to compare their relative and joint effects on carbon fluxes. Firstly, we found that foliar fungi had large direct and indirect effects on ecosystem carbon fluxes, while soil fungi indirectly influenced mass-specific fluxes by reducing legumes and increasing $\mathrm{C} 4$ grasses, whereas arthropods had no direct or indirect effects on carbon fluxes. Neither soil fungi nor arthropods influenced plant biomass in our study, unlike previous studies that have shown significant effects of these heterotrophs on plant biomass, and diversity-production relationship (e.g., Schnitzer et al. 2010; Maron et al. 2011; Seabloom et al. 2017), partly explaining the lack of any effect on carbon fluxes. Our results highlight a potential critical role of foliar fungi in driving ecosystem functions compared with the well-studied effects of herbivores and soil fungi. In addition, our findings demonstrate that foodweb and plant community context mediate the response of carbon fluxes to removal of foliar fungi. Foliar fungi influenced carbon fluxes only when arthropods and soil fungi were present; when all three heterotroph groups were removed together, there was no significant effect on carbon fluxes even though arthropods or soil fungi did not independently alter carbon flux. The divergent effects of heterotrophs on plant community, and on intraspecific foliar N content can partly explain this finding. Specifically, while foliar fungi suppressed legumes and favored C4 grasses, arthropods had the opposite (although statistically insignificant) effect. Further, independent removal of foliar fungi and arthropods induces opposite effects on intraspecific foliar $\mathrm{N}$ content, which balance out when these are removed together (Borer et al. 2015). The presence of herbivores can also influence the severity of fungal infection in plants (Clay, Holah \& Rudgers 2005), potentially explaining why foliar fungi affected carbon fluxes only in the presence of other heterotrophs.

To reemphasize, we found that the effects of foliar fungi on carbon fluxes varied with the plant community and heterotroph foodweb context. Together, these findings demonstrate that the effects of biotic interactions, especially plant-pathogen interactions, on ecosystem processes such as carbon flux, are not easily predicted by species-specific and leaf-scale studies. Thus, long-term experiments such as the one in this study, that manipulate multiple biotic variables, are invaluable for revealing the complexity of ecosystems.

\section{Conclusions}

Our study underscores the importance of considering the effects of biotic interactions, especially between plants and foliar fungi, on ecosystem carbon fluxes in addition to carbon stocks (e.g., plant biomass). Together with previous studies, our results suggest that these interactions influence carbon fluxes by a combina- 
tion of effects ranging from leaf to community scale (Mitchell 2003; Borer et al. 2015; Seabloom et al. 2017). Foliar fungal endophytes and pathogens colonize the leaves of all plants (Rodriguez et al. 2009; Dobson \& Crawley 1994); examining whether the large effects of foliar fungi reported here are ubiquitous across biomes and ecosystems will shed light on the generality of our findings. The role of foliar fungi is likely to become even more important in the future with climatic changes (Harvell et al. 2002; Olofsson et al. 2011) and loss of plant diversity (Mitchell et al. 2002, Civitello et al. 2015), especially since we found that foliar fungi acted differently on carbon fluxes in low vs high plant diversity communities: they suppressed mass-specific flux rates in low diversity communities, but suppressed plant biomass in high diversity communities. These results further suggest that integrating plant disease ecology into global change and ecosystem ecology will be a fruitful avenue for additional research into human alterations of carbon cycling (Preston et al. 2016), as foliar fungi have large but largely unquantified effects on ecosystem flux rates.

\section{Acknowledgments}

This work was supported by grants from the US National Science Foundation Long-Term Ecological Research Program (LTER) including DEB-1234162 and DEB-1831944. Funding from the UMN Graduate School, from EEB and Cedar Creek supported MK. We are grateful to Troy Mielke, Jon Anderson, Anita Krause, Susan Barott and Dan Bahauddin for logistical support, Sarah Hobbie and Forest Isbell for comments on the manuscript, Evelyn Hayhurst, Katherine Schroeder, Megan Wilcots, Lucas Bowerman and Cedar Creek interns for their help in data collection.

\section{References}

Allan, E., Van Ruijven, J., \& Crawley, M. J. (2010). Foliar fungal pathogens and grassland biodiversity. Ecology , 91 (9), 2572-2582.

Anderson, P. K., Cunningham, A. A., Patel, N. G., Morales, F. J., Epstein, P. R., \& Daszak, P. (2004). Emerging infectious diseases of plants: pathogen pollution, climate change and agrotechnology drivers. Trends in ecology 83 evolution, 19 (10), 535-544.

Bates, D., Maechler, M., \& Bolker, B. S. Walker (2015). Fitting Linear Mixed-Effects Models Using lme4. Journal of Statistical Software, 67 (1), 1-48.

Barnosky, A. D., Matzke, N., Tomiya, S., Wogan, G. O., Swartz, B., Quental, T. B., .. \& Mersey, B. (2011). Has the Earth's sixth mass extinction already arrived?. Nature , 471 (7336), 51-57.

Beer, C., Reichstein, M., Tomelleri, E., Ciais, P., Jung, M., Carvalhais, N., .. \& Bondeau, A. (2010). Terrestrial gross carbon dioxide uptake: global distribution and covariation with climate. Science, 329 (5993), 834-838.

Bilgin, D. D., Zavala, J. A., Zhu, J. I. N., Clough, S. J., Ort, D. R., \& DeLUCIA, E. H. (2010). Biotic stress globally downregulates photosynthesis genes. Plant, cell $\&$ environment , 33 (10), 1597-1613.

Bolan, N. S. (1991). A critical review on the role of mycorrhizal fungi in the uptake of phosphorus by plants. Plant and soil , 134 (2), 189-207.

Borer, E. T., Lind, E. M., Ogdahl, E. J., Seabloom, E. W., Tilman, D., Montgomery, R. A., \& Kinkel, L. L. (2015). Food-web composition and plant diversity control foliar nutrient content and stoichiometry. Journal of Ecology , 103 (6), 1432-1441.

Cappelli, S. L., Pichon, N. A., Kempel, A., \& Allan, E. (2020). Sick plants in grassland communities: a growth-defense trade-off is the main driver of fungal pathogen abundance. Ecology Letters . https://doi.org/10.1111/ele.13537

Ceballos, G., Ehrlich, P. R., \& Dirzo, R. (2017). Biological annihilation via the ongoing sixth mass extinction signaled by vertebrate population losses and declines. Proceedings of the national academy of sciences, 114 (30), E6089-E6096. 
Civitello, D. J., Cohen, J., Fatima, H., Halstead, N. T., Liriano, J., McMahon, T. A., .. \& Rohr, J. R. (2015). Biodiversity inhibits parasites: broad evidence for the dilution effect. Proceedings of the National Academy of Sciences , 112 (28), 8667-8671.

Clay, K., Holah, J., \& Rudgers, J. A. (2005). Herbivores cause a rapid increase in hereditary symbiosis and alter plant community composition. Proceedings of the National Academy of Sciences , 102 (35), 12465-12470.

Dirzo, R., Young, H. S., Galetti, M., Ceballos, G., Isaac, N. J., \& Collen, B. (2014). Defaunation in the Anthropocene. science, 345 (6195), 401-406.

Dobson, A., \& Crawley, M. (1994). Pathogens and the structure of plant communities. Trends in Ecology $\mathscr{E}$ Evolution , 9 (10), 393-398.

Eisenhauer, N., Reich, P. B., \& Isbell, F. (2012). Decomposer diversity and identity influence plant diversity effects on ecosystem functioning. Ecology , 93 (10), 2227-2240.

El-Hajj, Z., Kavanagh, K., Rose, C., \& Kanaan-Atallah, Z. (2004). Nitrogen and carbon dynamics of a foliar biotrophic fungal parasite in fertilized Douglas-fir. New Phytologist , 163 (1), 139-147.

Garrett, K. A., Dendy, S. P., Frank, E. E., Rouse, M. N., \& Travers, S. E. (2006). Climate change effects on plant disease: genomes to ecosystems. Annu. Rev. Phytopathol. , 44 , 489-509.

Gastine, A., Scherer-Lorenzen, M., \& Leadley, P. W. (2003). No consistent effects of plant diversity on root biomass, soil biota and soil abiotic conditions in temperate grassland communities. Applied soil ecology , 24 (1), 101-111.

Guiz, J., Hillebrand, H., Borer, E. T., Abbas, M., Ebeling, A., Weigelt, A., . . \& Weisser, W. W. (2016). Long-term effects of plant diversity and composition on plant stoichiometry. Oikos , 125 (5), 613-621.

Guiz, J., Ebeling, A., Eisenhauer, N., Hacker, N., Hertzog, L., Oelmann, Y., .. \& Hillebrand, H. (2018). Interspecific competition alters leaf stoichiometry in 20 grassland species. Oikos , 127 (7), 903-914.

Hallmann, C. A., Sorg, M., Jongejans, E., Siepel, H., Hofland, N., Schwan, H., .. \& Goulson, D. (2017). More than 75 percent decline over 27 years in total flying insect biomass in protected areas. PloS one , 12 (10), e0185809.

Harvell, C. D., Mitchell, C. E., Ward, J. R., Altizer, S., Dobson, A. P., Ostfeld, R. S., \& Samuel, M. D. (2002). Climate warming and disease risks for terrestrial and marine biota. Science, 296 (5576), 2158-2162.

Hobbie, S. E., \& Villéger, S. É. B. A. S. T. I. E. N. (2015). Interactive effects of plants, decomposers, herbivores, and predators on nutrient cycling. Trophic Interactions: Bottom-up and Top-down Interactions in Aquatic and Terrestrial Ecosystems, 233-259.

Kohli, M., Borer, E. T., Kinkel, L., \& Seabloom, E. W. (2019). Stability of grassland production is robust to changes in the consumer food web. Ecology letters, 22 (4), 707-716.

Lambers, H., Chapin III, F. S., \& Pons, T. L. (2008). Plant physiological ecology . Springer Science \& Business Media.

Lasslop, G., Reichstein, M., Papale, D., Richardson, A. D., Arneth, A., Barr, A., .. \& Wohlfahrt, G. (2010). Separation of net ecosystem exchange into assimilation and respiration using a light response curve approach: critical issues and global evaluation. Global Change Biology , 16 (1), 187-208.

Lefcheck, J. S. (2016). piecewiseSEM: Piecewise structural equation modelling in $\mathrm{r}$ for ecology, evolution, and systematics. Methods in Ecology and Evolution, 7 (5), 573-579.

Loboda, S., Savage, J., Buddle, C. M., Schmidt, N. M., \& Høye, T. T. (2018). Declining diversity and abundance of High Arctic fly assemblages over two decades of rapid climate warming. Ecography , 41 (2), 265-277. 
Maron, J. L., Marler, M., Klironomos, J. N., \& Cleveland, C. C. (2011). Soil fungal pathogens and the relationship between plant diversity and productivity. Ecology letters , 14 (1), 36-41.

McCauley, D. J., Pinsky, M. L., Palumbi, S. R., Estes, J. A., Joyce, F. H., \& Warner, R. R. (2015). Marine defaunation: animal loss in the global ocean. Science, 347 (6219), 1255641.

McGrady-Steed, J., Harris, P. M., \& Morin, P. J. (1997). Biodiversity regulates ecosystem predictability. Nature, 390 (6656), 162-165.

Milcu, A., Roscher, C., Gessler, A., Bachmann, D., Gockele, A., Guderle, M., .. \& Ravel, O. (2014). Functional diversity of leaf nitrogen concentrations drives grassland carbon fluxes. Ecology letters , 17 (4), 435-444.

Mitchell, C. E., Tilman, D., \& Groth, J. V. (2002). Effects of grassland plant species diversity, abundance, and composition on foliar fungal disease. Ecology , 83 (6), 1713-1726.

Mitchell, C. E. (2003). Trophic control of grassland production and biomass by pathogens. Ecology Letters , 6 (2), 147-155.

Naeem, S., Thompson, L. J., Lawler, S. P., Lawton, J. H., \& Woodfin, R. M. (1994). Declining biodiversity can alter the performance of ecosystems. Nature, 368 (6473), 734-737.

Nabity, P. D., Zavala, J. A., \& DeLucia, E. H. (2009). Indirect suppression of photosynthesis on individual leaves by arthropod herbivory. Annals of botany , 103 (4), 655-663.

O'Connor, M. I., Gonzalez, A., Byrnes, J. E., Cardinale, B. J., Duffy, J. E., Gamfeldt, L., ... \& Thompson, P. L. (2017). A general biodiversity-function relationship is mediated by trophic level. Oikos , 126 (1), 18-31.

Olofsson, J., Ericson, L., Torp, M., Stark, S., \& Baxter, R. (2011). Carbon balance of Arctic tundra under increased snow cover mediated by a plant pathogen. Nature climate change, 1 (4), 220-223.

Pastor, J., \& Cohen, Y. (1997). Herbivores, the functional diversity of plants species, and the cycling of nutrients in ecosystems. Theoretical Population Biology , 51 (3), 165-179.

Pastor, J., Dewey, B., Naiman, R. J., McInnes, P. F., \& Cohen, Y. (1993). Moose browsing and soil fertility in the boreal forests of Isle Royale National Park. Ecology , 74 (2), 467-480.

Pinheiro, J., Bates, D., DebRoy, S., \& Sarkar, D. (2019). R Core Team. 2019. nlme: linear and nonlinear mixed effects models. R package version 3.1-141. Available at $h$ Ttp://CRAN. R-Project. Org/Package= Nlme .

Preston, D. L., Mischler, J. A., Townsend, A. R., \& Johnson, P. T. (2016). Disease ecology meets ecosystem science. Ecosystems , 19 (4), 737-748.

Reich, P. B., Walters, M. B., \& Ellsworth, D. S. (1997). From tropics to tundra: global convergence in plant functioning. Proceedings of the National Academy of Sciences , 94 (25), 13730-13734.

Reich, P. B., Tjoelker, M. G., Machado, J. L., \& Oleksyn, J. (2006). Universal scaling of respiratory metabolism, size and nitrogen in plants. Nature , 439 (7075), 457-461.

Reich, P. B., Tjoelker, M. G., Pregitzer, K. S., Wright, I. J., Oleksyn, J., \& Machado, J. L. (2008). Scaling of respiration to nitrogen in leaves, stems and roots of higher land plants. Ecology letters , 11 (8), 793-801.

Ritchie, M. E., Tilman, D., \& Knops, J. M. (1998). Herbivore effects on plant and nitrogen dynamics in oak savanna. Ecology, 79 (1), 165-177.

Rodriguez, R. J., White Jr, J. F., Arnold, A. E., \& Redman, A. R. A. (2009). Fungal endophytes: diversity and functional roles. New phytologist, 182 (2), 314-330.

Rosenberg, K. V., Dokter, A. M., Blancher, P. J., Sauer, J. R., Smith, A. C., Smith, P. A., .. \& Marra, P. P. (2019). Decline of the North American avifauna. Science, 366 (6461), 120-124. 
Seabloom, E. W., Borer, E. T., \& Kinkel, L. L. (2018). No evidence for trade-offs in plant responses to consumer food web manipulations. Ecology, 99 (9), 1953-1963.

Seabloom, E. W., Kinkel, L., Borer, E. T., Hautier, Y., Montgomery, R. A., \& Tilman, D. (2017). Food webs obscure the strength of plant diversity effects on primary productivity. Ecology letters , 20 (4), 505-512.

Seibold, S., Gossner, M. M., Simons, N. K., Bluthgen, N., Muller, J., Ambarll, D., .. \& \& Linsenmair, K. E. (2019). Arthropod decline in grasslands and forests is associated with landscape-level drivers. Nature, 574 (7780), 671-674.

Schmitz, O. J. (2010). Resolving ecosystem complexity (MPB-47) (Vol. 47). Princeton University Press.

Schnitzer, S. A., Klironomos, J. N., HilleRisLambers, J., Kinkel, L. L., Reich, P. B., Xiao, K., .. \& Van Nes, E. H. (2011). Soil microbes drive the classic plant diversity-productivity pattern. Ecology , 92 (2), 296-303.

Smith, S. E., \& Read, D. J. (2008). Mineral nutrition, toxic element accumulation and water relations of arbuscular mycorrhizal plants. Mycorrhizal symbiosis , 3 , 145-18.

Stocker, R., Körner, C., Schmid, B., Niklaus, P. A., \& Leadley, P. W. (1999). A field study of the effects of elevated $\mathrm{CO} 2$ and plant species diversity on ecosystem-level gas exchange in a planted calcareous grassland. Global Change Biology , 5 (1), 95-105.

Strengbom, J., Nordin, A., Nasholm, T., \& Ericson, L. (2002). Parasitic fungus mediates change in nitrogenexposed boreal forest vegetation. Journal of Ecology, 90 (1), 61-67.

Strickland, M. S., Hawlena, D., Reese, A., Bradford, M. A., \& Schmitz, O. J. (2013). Trophic cascade alters ecosystem carbon exchange. Proceedings of the National Academy of Sciences , 110 (27), 11035-11038.

Tilman, D., Reich, P. B., Knops, J., Wedin, D., Mielke, T., \& Lehman, C. (2001). Diversity and productivity in a long-term grassland experiment. Science, 294 (5543), 843-845.

Tjoelker, M. G., Craine, J. M., Wedin, D., Reich, P. B., \& Tilman, D. (2005). Linking leaf and root trait syndromes among 39 grassland and savannah species. New Phytologist , 167 (2), 493-508.

van Klink, R., Bowler, D. E., Gongalsky, K. B., Swengel, A. B., Gentile, A., \& Chase, J. M. (2020). Metaanalysis reveals declines in terrestrial but increases in freshwater insect abundances. Science , 368 (6489), 417-420.

Wang, L., Delgado-Baquerizo, M., Wang, D., Isbell, F., Liu, J., Feng, C., .. \& \& Chang, Q. (2019). Diversifying livestock promotes multidiversity and multifunctionality in managed grasslands. Proceedings of the National Academy of Sciences , 116 (13), 6187-6192.

H. Wickham. ggplot2: Elegant Graphics for Data Analysis. Springer-Verlag New York, 2009.

Williams, M., Rastetter, E. B., Van der Pol, L., \& Shaver, G. R. (2014). Arctic canopy photosynthetic efficiency enhanced under diffuse light, linked to a reduction in the fraction of the canopy in deep shade. New Phytologist, 202 (4), 1267-1276.

Wilsey, B. J., \& Polley, H. W. (2004). Realistically low species evenness does not alter grassland speciesrichness-productivity relationships. Ecology , 85 (10), 2693-2700.

Wright, I. J., Reich, P. B., Westoby, M., Ackerly, D. D., Baruch, Z., Bongers, F., .. \& Flexas, J. (2004). The worldwide leaf economics spectrum. Nature, 428 (6985), 821-827.

Yang, Y., Tilman, D., Furey, G., \& Lehman, C. (2019). Soil carbon sequestration accelerated by restoration of grassland biodiversity. Nature communications , 10 (1), 1-7.

Young, H. S., McCauley, D. J., Galetti, M., \& Dirzo, R. (2016). Patterns, causes, and consequences of anthropocene defaunation. Annual Review of Ecology, Evolution, and Systematics , 47 , 333-358. 
Figure 1. Hypothetical effect of plant species richness and heterotroph presence on ecosystem flux per unit area (panel C) is a joint outcome of effects of plant species richness and heterotroph presence on mass-specific flux (panel A) and plant biomass per unit area (panel B). While the increase in biomass per unit area with increasing diversity and upon removal of heterotrophs (B) is well established (e.g., Seabloom et al. 2017), it is less clear how mass-specific fluxes are impacted by biodiversity and presence of heterotrophs. Variation in mass-specific flux (A) could lead to a large variation in total flux per unit area $(\mathrm{C})$. Line color indicates the effects of presence (red) or absence (blue) of heterotrophs on flux and biomass. Line type indicates whether flux per unit plant biomass increases (solid), remains constant (dotted) or declines (dashed) with plant diversity.
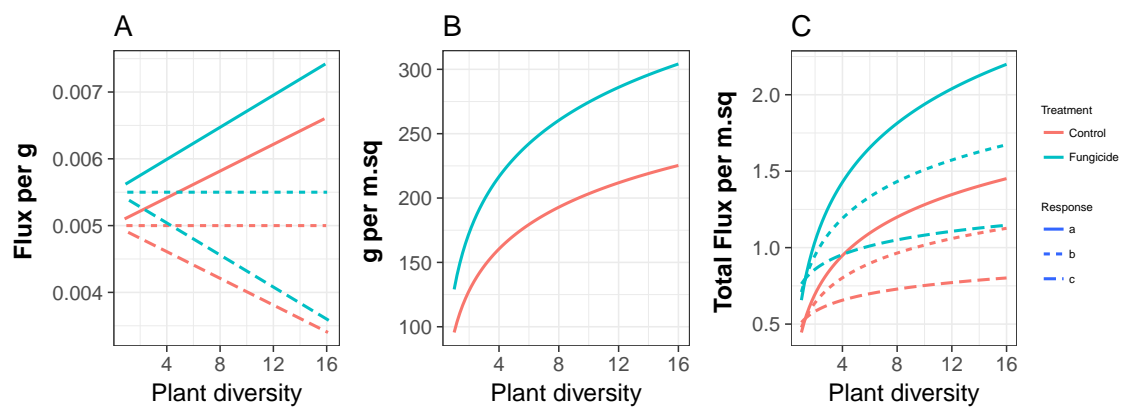

Figure 2. Measured fluxes of $\mathrm{CO} 2$ at the plot scale along a gradient of planted species richness in various removal treatments. A) Ecosystem respiration, B) Gross primary productivity and C) Net ecosystem exchange of $\mathrm{C}$ (mean +/- 1 s.e.m) in micromoles of $\mathrm{CO} 2$ per square meter per second. Negative values of NEE indicate net capture of carbon whereas positive values indicate net release.
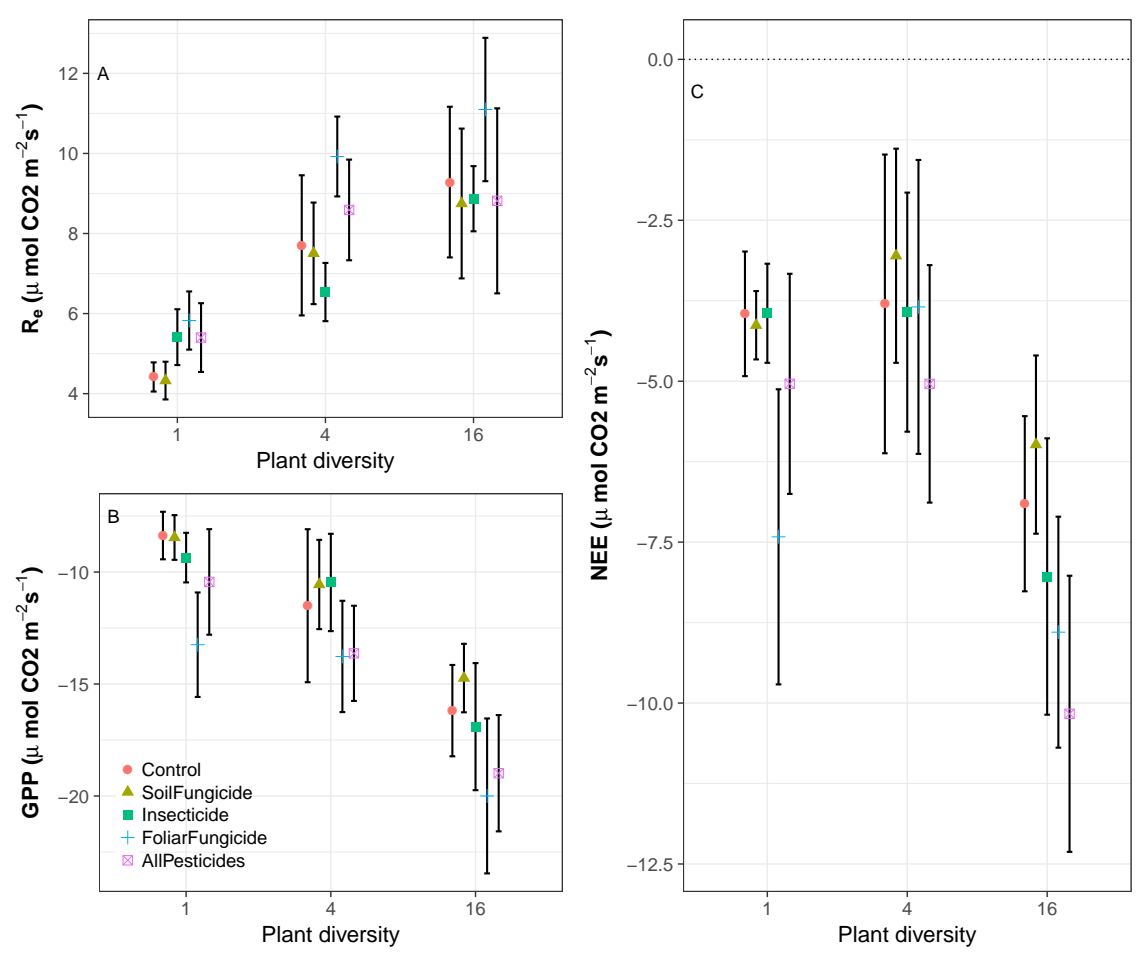
Figure 3. Measured fluxes of $\mathrm{CO} 2$ per $g$ of total plant biomass at the plot scale along a gradient of planted species richness (1, 4 and 16 species plots) in various removal treatments. A) Ecosystem respiration, B) Gross primary productivity and C) Net ecosystem exchange of CO2 (mean +/- 1 s.e.m) in micromoles of $\mathrm{CO} 2$ per g plant biomass per square meter per second. Negative values indicate carbon uptake whereas positive values indicate carbon release.
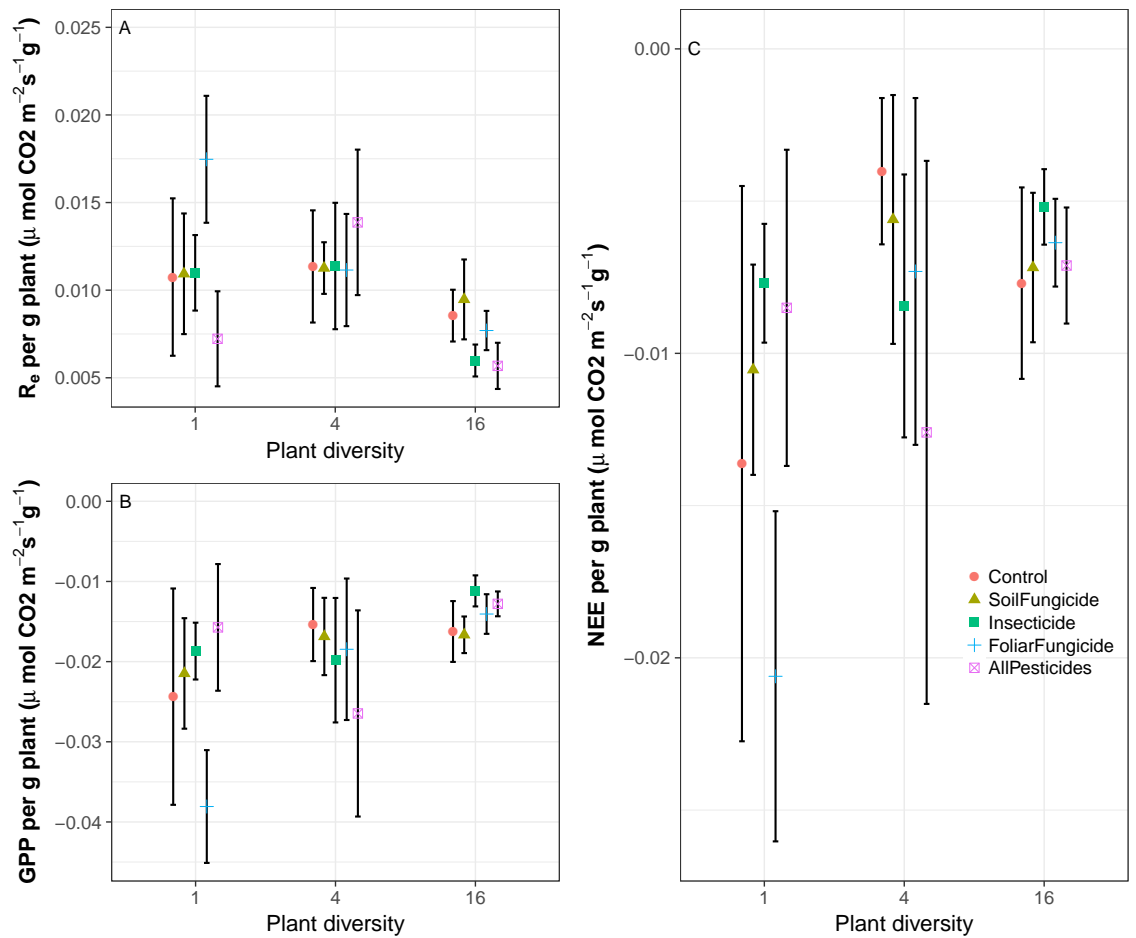

Figure 4. Mass-specific fluxes (A, B: $\mathrm{R}_{\mathrm{e}}$; C,D: GPP) declined with increasing belowground plant biomass $(\mathrm{A}, \mathrm{C})$ and increasing abundance of $\mathrm{C} 4$ grasses $(\mathrm{B}, \mathrm{D})$. Negative flux values indicate carbon uptake and positive values indicate carbon release. Point size corresponds to plant diversity and symbol to consumer removal. 

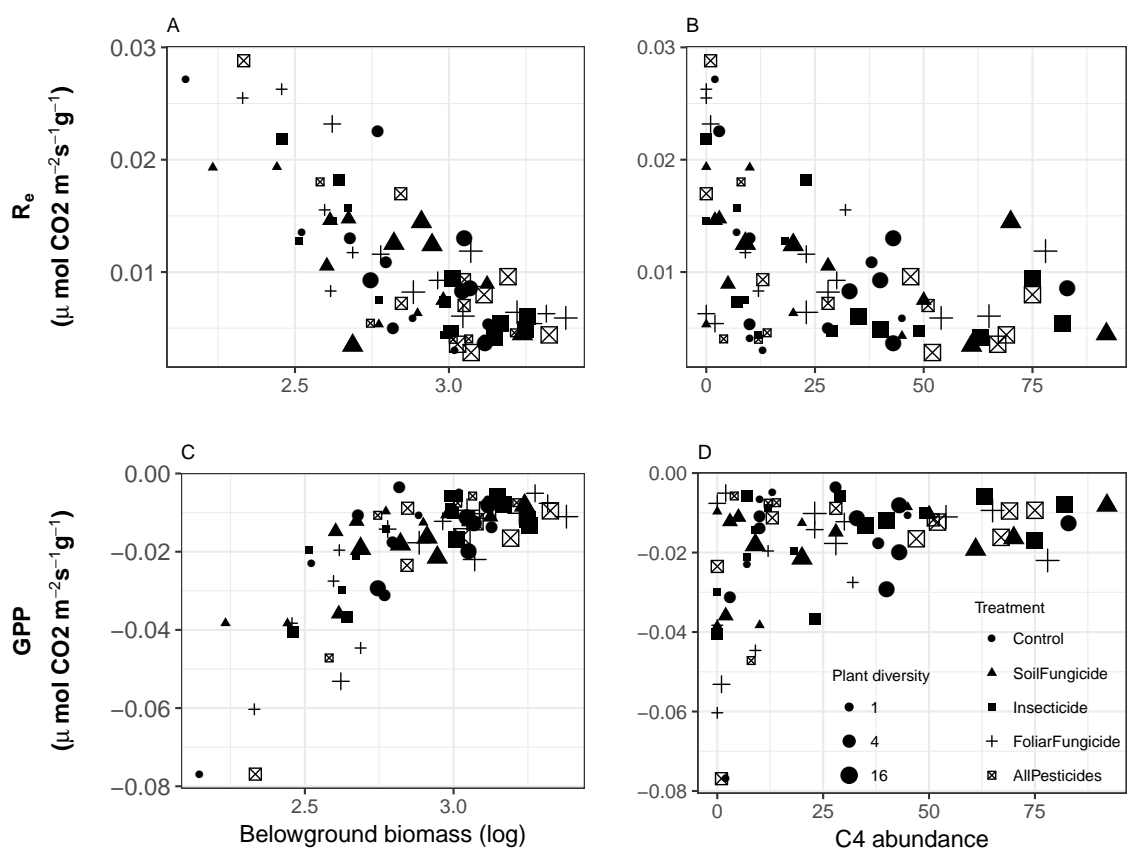

Figure 5. Mass-specific carbon fluxes increased with increasing foliar nitrogen (N) content. Foliar N data shown here averaged across the community. Note that regression is of the type $\mathrm{Y}=\mathrm{aX} \mathrm{X}^{\mathrm{b}}$ fit in its logarithmic form following Reich et al. (1997). Axes are on the log scale.
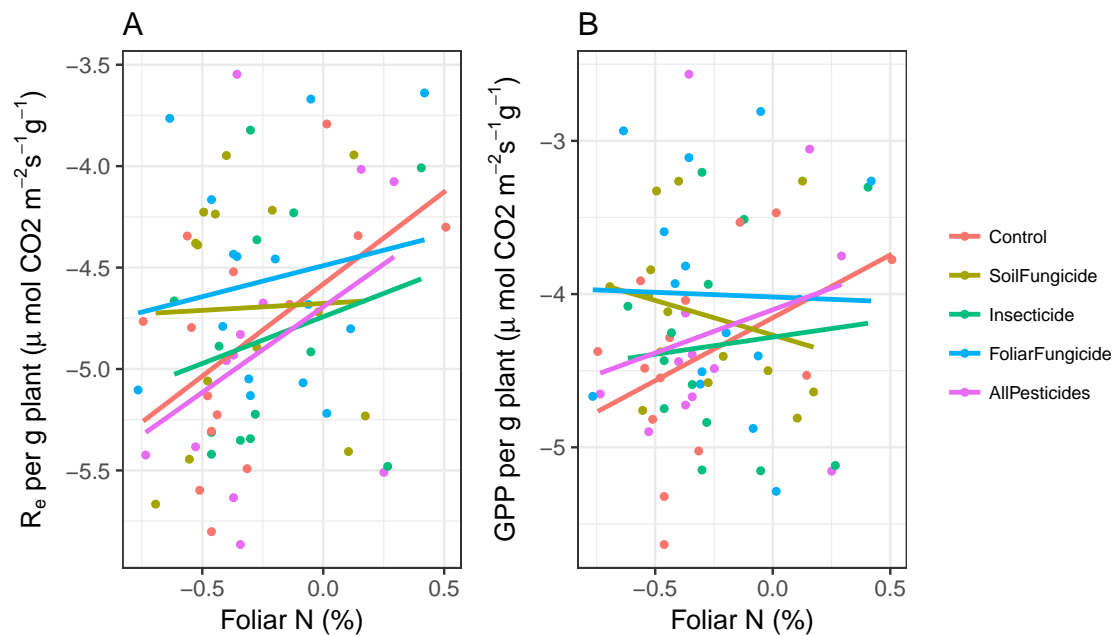

Figure 6. Community wide foliar $\mathrm{N}$ content declined with increasing belowground biomass (left panel) and relative abundance of $\mathrm{C} 4$ grasses (right panel). 

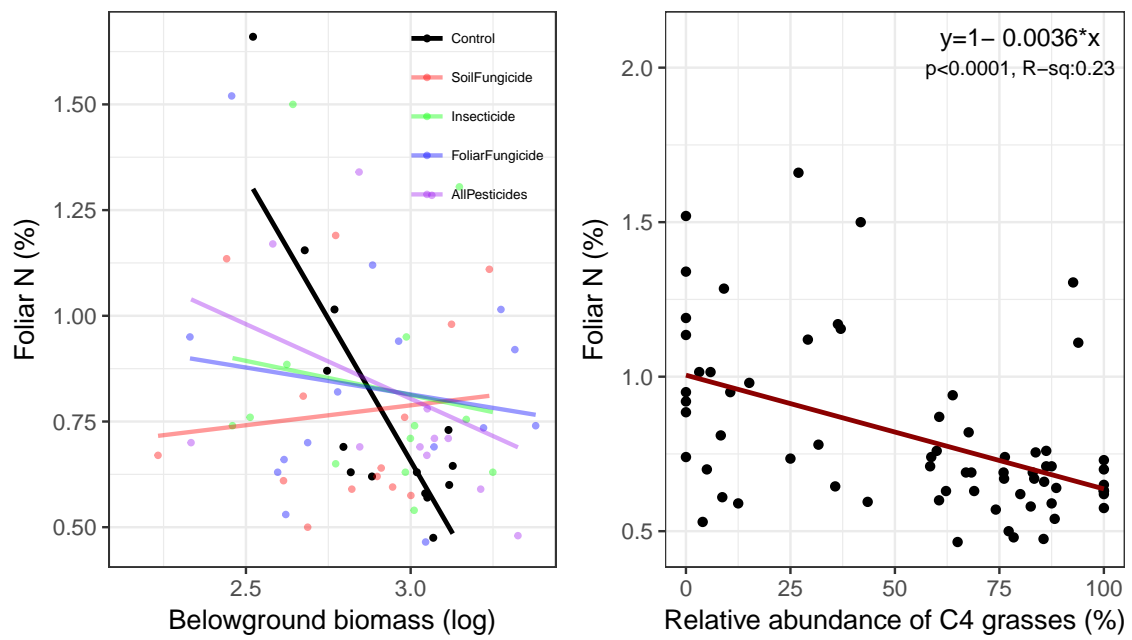